\title{
O cuidado como uma Lei da Natureza: uma percepção integral do cuidar
}

\author{
CARE AS A NATURE LAW: AN INTEGRAL PERCEPTION OF CARING
}

EL CUIDADO COMO UNA LEY DE LANATURALEZA: UNA PERCEPCIÓN INTEGRAL DEL CUIDADO

\author{
Pablo Santos Lira ${ }^{1}$, Maria Júlia Paes da Silva ${ }^{2}$
}

\section{RESUMO}

Este trabalho faz uma reflexão entre a percepção do cuidar pelo profissional de enfermagem e a relação do significado dado ao termo Cuidar, que é um instrumento norteador da qualidade da assistência. Questiona o nível de profundidade do significado que essa palavra pode assumir, identificando sua presença em todos os processos do Universo e na história mitológica do ser humano. Propõe que o cuidar é a Lei que permite a manifestação dos potenciais de organização numa certa direção de estabilidade dinâmica, manifestos na matéria, até a promoção e estabelecimento da saúde e do bem-estar. Concluiu-se, afirmando que a Lei do Cuidar pode ser entendida como um conjunto de forças que permitem o prolongamento ou abreviamento de certo grau de organização, que pode ser expresso em diversos níveis.

\section{DESCRITORES}

Antropologia cultural.

Conhecimentos, atitudes e

prática em saúde.

Cuidados de enfermagem.

\section{ABSTRACT}

This paper is a reflection on the perception of care nursing professionals have and the meaning given to the term, which is a tool for directing the quality of the assistance. It questions the level of depth that this word may have, identifying its presence in all processes of the Universe and throughout mankind's mythological history. It proposes that caring is the law that makes possible the manifestation of the organization potential in a given direction of dynamic stability, seen in matter, which unfolds into the promotion and establishment of health and well-being. It concludes by stating that the Law of Care may be understood as a set of forces that make possible the extension or abbreviation of a given degree of organization that may be expressed in different levels.

\section{KEY WORDS}

Anthropology, cultural. Health knowledge, Attitudes, practice. Nursing care.

\section{RESUMEN}

En este trabajo se hace una reflexión entre la percepción del cuidar por el profesional de enfermería y la relación del significado dado al término Cuidar, que es un instrumento norteador de la calidad de la asistencia. Cuestiona el nivel de profundidad del significado que esa palabra puede asumir, identificando su presencia en todos los procesos del Universo y en la historia mitológica del ser humano. Propone que el cuidar es la Ley que permite la manifestación de los potenciales de organización en una determinada dirección de estabilidad dinámica, manifestados en la materia, hasta la promoción y el establecimiento de la salud y del bienestar. Se concluye con la afirmación de que la Ley del Cuidar puede ser entendida como un conjunto de fuerzas que permiten la prolongación o brevedad de cierto grado de organización, que puede ser expresado en diversos niveles.

\section{DESCRIPTORES}

Antropología cultural. Conocimientos, actitudes y práctica en salud. Atención de enfermería.

${ }^{1}$ Graduando de Enfermagem da Escola de Enfermagem da Universidade de São Paulo (EEUSP). São Paulo, SP, Brasil. egonstrauss@yahoo.com.br ${ }^{2}$ Professora Titular do Departamento de Enfermagem Médico-Cirúrgico da EEUSP. São Paulo, SP, Brasil. juliaps@usp.br 


\section{INTRODUÇÃO}

Deus criou o homem, pois gostava de ouvir histórias. Somos contadores e construtores de estórias e da história, na qual o ser humano é obra de uma longa jornada evolutiva de mutações e seleções geradas a partir de pressões naturais advindas do meio e pressões artificiais vindas do desenvolvimento das relações culturais ${ }^{(1-2)}$.

Nessa estrada evolutiva as informações vão sendo armazenadas de duas formas: uma intragenética e a outra extragenética. Na primeira, os dados biológicos são armazenados na forma de um complexo sistema de montagem e gerenciamento do organismo que envolve um sistema extremamente dinâmico e flexível condutor do organismo sobre a Terra, responsável para que o ser consiga transmitir seu material gênico de modo que suplante as pressões seletivas do meio e consiga copular ${ }^{(3)}$.

Na segunda, a decodificação e armazenamento dos dados extraídos da realidade são gerenciados e transmitidos por um sistema que denominamos Cultura ${ }^{(2)}$, presente também em diversas espécies de aves e símios, porém expresso de modo mais proeminente na espécie Homo sapiens. Os traços culturais que se manifestam em diversos graus em toda a espécie são basicamente quatro: as Artes, as Ciências, as Tecnologias e as Religiões ${ }^{(2)}$.

De modo similar ao ADN, que a partir da combinação das quatro bases nitrogenadas $^{(3-4)}$ (timina, citosina, guanina e adenina), promovem a transmissão e armazenamento das informações, e criam as unidades biológicas e os degraus da escalada evolutiva, a cultura também possui suas quatro bases (as Artes, as Ciências, as Tecnologias e as Religiões) que, ao interagirem, criam unidades ideológicas, simbólicas e comportamentais interativas ${ }^{(5)}$.

As duas interagem com a realidade, tanto a primeira quanto a segunda. Na primeira, os avanços ocorrem através das mutações e pressões seletivas do meio(1) , e coincidência ou não, a segunda também, pois os grandes avanços sejam nas artes, ciências ou religiões, ocorrem por meio de um gênio ou profeta, que dentre certa comunidade ou mentalidade vigente é o mutante que impregna e modificatc. É difícil afirmar até que ponto estes fatos são acasos ou realidades, e o objetivo deste trabalho é trazer novas reflexões sobre conceitos e palavras há muito usadas, diretamente relacionadas ao cuidar.

Segundo o exposto, tanto o mutante biológico, como o mutante ideológico (o indivíduo que desencadeia uma alteração dos conceitos vigentes em qualquer um dos pilares da Cultura) criam novas percepções e interações com a Natureza que o permeia, seja aperfeiçoando algo já realizado ou inovando plenamente. Para ilustrar tal idéia na alteração biológica, podemos citar o desenvolvimento do rúmen nos ruminantes que permitiu a eles digerirem a celulose, ou o desenvolvimento de ossos pneumáticos nas aves aladas ${ }^{(4)}$

No caso do mutante ideológico, podemos citar a revolução gravitacional de Newton ${ }^{(7)}$, baseado na física clássica; a elegância da gravidade geométrica de Albert Einstein $^{(7)}$, que culminou na Teoria da Relatividade Geral e Restrita; os conceitos sociais propostos por Jesus Cristo(8); a revolução biológica de Charles Darwin ${ }^{(1,7)}$; o mecanismo de emissão radioativa atômica proposta por Madame Curie ${ }^{(7)}$; entre outros incontáveis gênios científicos, artísticos e sociais.

Permitindo-se refletir sobre a grande influência do mutante ${ }^{(3-6)}$ ideológico selecionado, poderia-se questionar se o átomo proposto por Demócrito e outros tantos gregos, não é o mesmo átomo da Física quântica(9-10); ou se o mesmo deus Sol ou Áton, adorado pelos egípcios, não é o mesmo Sol da Astrofísica moderna, que compreende a ação do campo gravitacional e as reações nucleares; ou ainda, se a transcendência apregoada por Buda e Jesus, não é a mesma dos conceitos modernos da Inteligência Emocional(11) e Inteligência Espiritual| ${ }^{(12)}$.

A resposta a tais questionamentos pode parecer ambígua, mas o fato é que sim e não. Vários autores afirmam que o que os antigos percebiam intuitivamente e Albert Einstein comprovou matematicamente, está correto, ou seja, tudo é relativo e somente o que é estranho causa estranhamento(9-13).

A percepção da realidade possui bases semelhantes, mas muitas vezes são requeridos novos argumentos e conceitos para um entendimento mais profundo da realidade e da Nature$\mathrm{za}^{(10)}$. Assim sendo, os conceitos introduzidos pelos M utantes ideológicos ${ }^{(6)}$ permitem uma nova percepção de um fato antigo e, neste contexto, podem desencadear novos processos intelectuais, técnicos, emocionais e espirituais, sob o conceito no qual agem.

0 presente trabalho se propõe a fazer uma nova reflexão sobre o cuidar. Desde quando existe? Faz parte somente dos seres viventes? Onde está o cuidar? Será uma Lei da Natureza? A questão que talvez envolva de modo mais adequado esta nova reflexão sobre o cuidar é: o cuidar é uma Lei da Natureza?

\section{O CUIDADO COMO POTENCIAL DE ORGANIZAÇÃO E NO MUNDO MÍTICO}

Talvez sim, talvez não. Neste contexto da reflexão inicial, o cuidar é o conjunto de situações e elementos agentes que criam situações para que certos potenciais despertem e se manifestem numa certa direção. 
De modo geral, o presente trabalho propõe que o cuidar é a Lei que permite a manifestação dos Potenciais de organização. Em síntese, cuidar é a Lei que permite a manifestação dos Potenciais de organização numa certa direção de estabilidade dinâmica, manifestos na matéria, até a promoção e restabelecimento da saúde e do bem estar.

\section{Como exemplo de Potenciais de Organização, tem-se:}

- Cuidado no Universo - potenciais de organização manifestos na forma de galáxias, planetas e estrelas;

- Cuidado na Natureza - potenciais de organização manifestos nos ecossistemas e relação entre os seres vivos;

- Cuidado no mundo microcósmico - potenciais de organização manifestos na ordenação da matéria;

- Cuidado nos processos de saúde e doença - potenciais de organização manifestos nas dinâmicas de saúde e doença;

- Cuidado entre os seres humanos - potenciais de organização manifestos nos gestos e comportamentos humanos;

- Cuidado no mundo microbiano - potenciais de organização manifestos em microrganismos patogênicos ou não.

Por outro lado, no mundo mítico, todas as angústias humanas podem ser respondidas, diferentemente da ciência, que nem tudo pode solucionar. A ciência avança pelo terreno do palpável, das medidas, das observações diretas, dos dados concretos; o mito vai além, enquanto as explicações científicas seguem na estrada da linearidade, o mito caminha pelo complexo e mergulha na essência da existência humana. Fato observado na fábulamito sobre o cuidado $^{(14)}$ :

Certo dia ao atravessar um rio, Cuidado viu um pedaço de barro. Logo teve uma idéia inspirada. Tomou um pouco de barro e começou a dar lhe forma. Enquanto contemplava o que havia feito apareceu Júpiter. Cuidado pediu-lhe que soprasse espírito nele. O que Júpiter fez de bom grado. Quando, porém, Cuidado quis dar um nome à criatura que havia moldado, Júpiter o proibiu. Exigiu que fosse imposto o seu nome. Enquanto Júpiter e Cuidado discutiam, surgiu, de repente, a Terra. Quis também ela conferir o seu nome à criatura, pois fora feita de barro, material do corpo da Terra. Originou-se então uma discussão generalizada. De comum acordo pediram a Saturno que funcionasse como árbitro. Este tomou a seguinte decisão que pareceu justa: Você, Júpiter, deu-lhe o espírito; receberá, pois, de volta este espírito por ocasião da morte dessa criatura. Você, Terra, deu-Ihe o corpo; receberá, portanto, também de volta o corpo quando esta criatura morrer. Mas como você, Cuidado, foi quem, por primeiro, moldou a criatura, ficará sob seus cuidados enquanto ela viver. $\mathrm{E}$ uma vez que entre vocês há acalorada discussão acerca do nome, decido eu: esta criatura será chamada Homem, isto é, feita de húmus, que significa terra fértil.

A fábula mostra a solução para duas questões fundamentais da existência humana: como surgimos e o porquê de estarmosna Terra. Segundo consta neste mito, Cura (na sua forma mais antiga, cura em latim se escrevia coera e era usado num contexto de relações de amor e de amizade) viu um pedaço de barro e logo teve uma idéia inspirada (a palavra inspiração advém do grego theopneustos, que significa sopro divino ou Deus dentro), depois da qual começou a dar forma ao barro(14).

Ao analisar-se a filologia das palavras Cura(14) e Inspiração ${ }^{(13)}$, pode-se extrair a seguinte essência interpretativa: cura ou cuidado refere-se as relações de amor ${ }^{(15)}$ ou afeto estabelecido entre elementos vivos; já a palavra inspiração nos remete a idéia de um princípio intrínseco agindo e criando o impulso criador que tudo cria e do qual tudo emerge. Ainda neste contexto, é possível observar que as relações ou estabelecimento de comunicação ou troca de informação entre elementos são impulsionadas por um Caos interno, um abismo primordial que desencadeia a organização do meio ${ }^{(16)}$.

Assim sendo, o cuidado é a relação entre elementos, os quais são organizados por um princípio interno intrínseco, ao qual pode-se denominar de Caos, ou princípio ordenador. Eros, deus grego do Amor, nasceu do Caos (Caos vem da palavra grega khínein, que quer dizer abismo) ${ }^{(15)}$. Desse modo, o Caos era concebido como o abismo profundo (algo indefinido, anterior a todas as coisas). Eros nasceu do Caos e de Nix (a Noite). A noite pôs um ovo fecundo(a). Dele nasceu Eros, o amor. Das duas metades da casca, nasceram o Céu (Urano) e a Terra (Gaia). Graças às forças de Eros, o Céu e a Terra se apaixonaram e geraram as diversas coisas existentes no mundo.

Para exemplificar de modo mais claro e coerente, podese citar diversos mitos da criação(17), seguidos de uma breve explanação que tenta identificar que o cuidar é a Lei que permite a manifestação dos Potenciais de organização. De um modo geral, percebe-se que todos os símbolos referentes à compreensão da cosmologia e cosmogonia são constituídos por dois grupos de símbolos centrais. No primeiro, observa-se principalmente as imagens e figuras da água (ou chuva), da serpente e do pássaro. No segundo, encontra-se imagens que estão associadas à lua, ao ciclo de vida vegetal, a rotação das estações e ao crescimento essencial para a perpetuação da vida(16).

- Mitologia Pré-Histórica: a magia da caça é manifesta pelos primeiros homens através de pinturas mágicas, que representavam o sucesso em suas caçadas. Essa crença permitiria que o potencial desejado se manifestasse, ou seja, o sucesso da captura de sua presa. Por tal razão, esses homens pré-históricos realizavam um cuidado, segundo a concepção proposta neste trabalho, que era efetuado pelo grupo, tanto no que se refere à realização da pintura mágica, quanto à manutenção da mesma ${ }^{(17)}$.

- Mitologia Assírio-Babilônica: o mito da criação é constituído por sete tábuas, constituído por variados textos religiosos que eram utilizados na biblioteca de d'Assourbanipal.

(a) A idéia do Ovo Primordial ${ }^{(16)}$ será desenvolvida mais adiante. 
Os textos datam do século VII d.C., mais duas reproduções que são ainda mais antigas. A água figura como 0 elemento primordial, sendo que da fusão da água doce (Apsou) e da água salgada (Tiamat) resultaram todos os seres, a começar pelos deuses. Aqui o cuidar, ou seja, a manifestação dos potenciais de organização, acontece quando as duas qualidades de água se fundem, pois então ocorre a manifestação do potencial para criação dos deuses e de todos os demais seres ${ }^{(17)}$.

- Mitologia Lituana: a base fundamental das crenças religiosas do povo lituano acontece através da adoração das forças da natureza, enxergando as florestas como sagradas e manifestando o culto aos animais, árvores, astros celestes e aos processos naturais como a morte. Neste último, ocorria o culto à alma dos mortos, que cria que a alma dos que partiam iria habitar a vida das árvores, passando depois pelo corpo de diversos animais. O Cuidar na interpretação da mitologia da morte lituana, se manifesta como 0 acolhimento da alma do que parte para o interior de outros seres vivos, vegetais ou animais; sendo que a morte permite que um novo potencial se manifeste, ou seja, o espírito passa a integrar a essência de outro ser da floresta(17).

- M itologia Hindu: segundo as tábuas de M anu, do ovo de Brama (o Supremo), Bramanda, nasceram os deuses, os mundos e toda a humanidade. No princípio das trevas surgiu Svayambhu, o Autônomo, o Involuído, que fez evoluir a totalidade. Criou as águas e nelas depôs sua semente. E disto resultou um Ovo de Ouro. E deste Ovo nasceu, por si mesmo, Brama, o Ancestral de todos os mundos. Nessas palavras é possível reconhecer que, a partir de um potencial intrínseco, ocorreu à manifestação do Autônomo e, por si só, este se revelou na forma de Brama ${ }^{(16)}$.

- M itologia Tibetana: no Tibete, o livro dos M ortos (Bardo Thödol) contém essas linhas sobre o Ovo Cósmico, que relata nos primeiros tempos de nosso planeta só um elemento era evoluído: o fogo. No nevoeiro de fogo, o Sangsâra, ou Cosmos, pôs-se em movimento rotativo etornouse um corpo globuloso, cintilante de forças primordiais não diferenciadas. Todos os outros elementos continuaram uns embriões. Primeiro a vida manifestou-se vestida deFogo e, seo homem existiu neste momento, ele possuía um corpo de fogo...(16). Quando o Cosmos se pôs em movimento rotativo, permitiu que ocorresse a manifestação de forças primordiais não diferenciadas, tornando o potencial de organização ainda não-manifesto, em manifesto; ou seja, realizou o cuidado segundo a reflexão da significância do termo cuidar.

- Mitologia Chinesa: segundo a mais antiga tradição chinesa, o Caos tinha a aparência de Ovo. Ao fim de 18.000 anos ele abriu-se. Os elementos pesados formaram Yin, a Terra; os elementos leves e puros Yang, o Céu. Todo o potencial estava contido no Ovo, que era a forma do caos; após sua abertura, o potencial de organização se manifestou no Yin e Yang ${ }^{(b)(16,18)}$.

(b) Princípio milenar que se refere a uma estruturação da realidade baseada na dualidade.
- M itologia no Japão: no começo era o Caos, semelhante a um oceano de óleo, ou a um Ovo, mal definido, mas portador de germes. Dessa confusão nasceu uma "coisa" semelhante a um broto de bambu, concebida como uma divindade e a quem deram nome... ${ }^{(16,18)}$. Do mesmo modo que nos exemplos anteriores, o potencial de organização contido no Caos manifestou os germes que existiam em si.

Após as citações de mitos, nos quais suas essências apresentam semelhanças fundamentais, é possível perceber certo potencial não manifesto que surge a partir de um Caos primordial(16): o nascimento do mundo ocorre a partir de um Ovo.

Pode-se afirmar como manifestação do potencial, que dentro de uma desordem aparente, como a agitação de moléculas de hélio ou o processo patológico de saúde, existe um sentido potencial de ordem que pode encaminhar-se para um grau maior ou menor de estabilidade.

\section{O CUIDADO E AS LEIS DE ESTRUTURAÇÃO DO UNIVERSO}

Como exposto anteriormente, o Cuidar seria o conjunto de condições que permite a manifestação de potenciais de organização num certo sentido. As leis do Universo que realizam a manifestação destes potenciais de organização são quatro, conhecidas a partir dos dados recentes da Física Quântica(10) e da Astrofísica Moderna ${ }^{(9-10)}$.

1) Força nuclear forte ou intra-atômica: força nuclear forte fornece a energia produzida nas estrelas; faz as estrelas brilharem e cria os raios resplandecentes e vivificantes do Sol. Se a força forte desaparecesse de repente, - Sol escureceria, extinguindo toda a vida na Terra. De fato, alguns cientistas acreditam que os dinossauros foram levados à extinção 65 milhões de anos atrás, quando fragmentos resultantes do impacto de um cometa foram arremetidos a grande altura na atmosfera, escurecendo a Terra e fazendo a temperatura em torno do planeta cair bruscamente. Ironicamente, é também a força nuclear forte que um dia pode tomar de volta o dom da vida. Liberada pela bomba de hidrogênio, a força nuclear forte poderia um dia matar toda a vida sobre a Terra ${ }^{(10)}$.

2) Força nuclear fraca ou inter atômica: a força nuclear fraca governa certas formas de desintegração radioativa. Como os materiais radioativos emitem calor quando se desintegram ou se rompem, a força nuclear fraca contribui para aquecer a rocha radioativa profundamente entranhada no interior da Terra. Esse calor, por sua vez, contribui para o calor produzido nos vulcões, as raras, mas possantes erupções de rocha liquefeita que chegam a superfície da Terra. As forças fraca e eletromagnética são utilizadas no tratamento de doenças graves: iodo radioativo é usado para extinguir tumores da tireóide e combater certas formas de câncer. A força da desintegração radioativa pode ser também mortal: ela causou a devas-

$36 \begin{array}{rr}\text { Rev Esc Enferm USP } \\ 2008 ; 42(2): 363-70 . & \text { O cuidado como uma Lei da Natureza: uma percepção } \\ \text { www.ee.usp.br/reeuspl } & \text { integral do cuidar - reflexões teóricas } \\ \text { Lira PS, Silva MJP }\end{array}$


tação em Three M ile Island e em Chernobyl; gera também lixo radioativo, o inevitável subproduto da produção de armas nucleares e das usinas elétricas nucleares, que podem permanecer nocivos por milhões de anos.

3) Força eletromagnética: força eletromagnética assume uma variedade de formas, entre as quais a eletricidade, o magnetismo e a própria luz. A força eletromagnética ilumina nossas cidades, transmite a música dos rádios e aparelhos de som, a imagem da televisão, reduz o trabaIho doméstico com os aparelhos elétricos, aquece a comida com microondas, rastreia os aviões e sondas espaciais com radares e eletrifica as usinas elétricas. Mais recentemente, o poder da força eletromagnética passou a ser usado em computadores eletrônicos (que revolucionou o escritório, a casa, a escola e as forças armadas) e em lasers (que introduziram novas perspectivas nas comunicações, na cirurgia, nos CDs, no armamento do Pentágono e até nos caixas eletrônicos nos Hipermercados). Mais da metade do Produto Nacional Bruto da Terra, representando a riqueza acumulada de nosso planeta, depende de algum modo da força eletromagnética.

4) Força gravitacional: força gravitacional mantém a Terra e os planetas em suas órbitas e aglutina a galáxia. Sem a força gravitacional da Terra, os seres humanos seriam arremessados no espaço pela rotação da Terra como bonecos. 0 ar que se respira se disseminaria rapidamente pelo espaço, levando-nos à asfixia e tornando a vida na Terra impossível. Sem a força gravitacional do Sol, todos os planetas, inclusive a Terra, seriam arremessados do sistema solar para os frios confins das profundezas do espaço, onde a luz solar é pálida demais para sustentar a vida. De fato, sem a força gravitacional, o próprio Sol explodiria. 0 Sol é o resultado de um delicado equilíbrio entre a força da gravidade, que tende a esmagá-lo, e a força nuclear, que tende a estilhaçá-lo. Sem gravidade, o Sol detonaria como trilhões e trilhões de bombas de hidrogênio. Estas quatro forças de organização do Universo, eletromagnética, gravitacional, nuclear forte e fraca, permitem que ocorra a manifestação de determinados potenciais de organização que emergem de uma desordem aparente, como nas citações míticas, na qual uma origem caótica e única, através de uma força de organização intrínseca, dá origem à manifestação da diversidade.

Quando as quatro leis interagem entre si, emerge tudo que se conhece no Universo, de nosso saber e cultura, pois elas edificam o que existe no mundo material denso ou sutil; realizam o Cuidar porque permitem a manifestação de potenciais. Aceitando-se essa idéia, pode-se pensar em fatos concretos e experimentais de nossa cultura humana que, segundo o já exposto, apóia-se em quatro bases: as Artes, as Ciências, as Tecnologias e as Religiões ${ }^{(2)}$.

É necessário mencionar que nosso atual questionamento sobre 0 universo exige algo primordial: é preciso que existamos, enquanto seres humanos. Isso pode parecer óbvio, mas esse fato é vital para a compreensão de como o Cuidar permitiu a manifestação da vida. No início, segundo as mais aceitas teorias sobre a Origem do Universo(9-10), essas quatro leis compunham uma única e estável manifestação, que era uma espécie de Ovo Primordial ${ }^{(16)}$. O que não se conhece até o momento, é o que desestabilizou tal unidade, mas existem diversas pesquisas no campo da física teórica para tentar explicar o porquê de tal fato, como por exemplo, a Teoria do Hiperespaço e do Universo Holográfico ${ }^{(10)}$.

Após a Grande Explosão(10), ou o que talvez se possa denominar de manifestação da Lei do Cuidar, o Universo começou a explicitar seus mais diversos potenciais de manifestação; ou seja, a partir da interação das quatro forças, ocorre o que se pode nomear de manifestação do Cuidar, o que significa a manifestação dos potenciais de organização não manifestos numa certa direção.

Nesse caso, seria a formação da organização do Universo e de tudo que existe nele, inclusive a manifestação da vida e dos seres autoconscientes. No que se refere à evolução orgânica, tem-se a formação dos primeiros ancestrais da vida, até a complexificação dos ecossistemas atuais(6), e com relação à evolução inorgânica, encontramos a modificação química das estruturas estelares, orgânicas e planetárias, por exemplo. Desse modo, pode-se averiguar que a partir da manifestação das quatro forças que estruturam o Universo, ocorreu a manifestação dos potenciais de organização ou Cuidar, no qual ocorre à formação das estrelas, dos planetas, dos ecossistemas, da relação do homem com a natureza, o surgimento das culturas, das artes, das tecnologias e das concepções religiosas; pois tudo que somos dependeu da Realidade até então manifesta pelo Universo, que varia do nível material, ao energético e do social ao espiritual.

\section{O CUIDAR NA NATUREZA E NO PROCESSO DE SAÚDE EM ENFERMAGEM}

A origem do Universo, segundo o renomado astrônomo da década de 40, George Gamow (que propôs, em 1947, a Teoria da Grande Explosão) (4), é uma monumental explosão, quando então tinha toda a sua massa concentrada num único ponto de tamanho infinitesimal, ocorrida entre 10 e 15 bilhões de anos. Nesse momento, conhecido como singularidade pelos estudiosos, surgiu simultaneamente 0 espaço, o tempo e toda a matéria e energia existente no universo, inclusive nosso planeta Terra(4). Assim como o próprio Universo sofreu um processo de evolução cosmológica, a Terra também.

A Terra passou pelo processo de resfriamento, formação da crosta e da atmosfera, fato este que dependeu de pontos como a temperatura do planeta, distância relativa do Sol, velocidade de rotação e formação das características próprias do globo. Após a evolução física da Terra, as quais pode-se englobar suas características físico-químicas, houve o desenvolvimento de uma complexificação 
da organização da matéria, que de modo bem sintético permitiu a origem das primeiras unidades pré-biológicas e, posteriormente, as biológicas. Na presente evolução planetária, graças a mecanismos que permitem a manifestação de certos potenciais de organização (lei do cuidar), os níveis de arranjo da matéria e dos organismos vivos compuseram o que é denominado de biosfera, organizada de um modo geral em: ecossistemas, comunidades, biótopo e populações ${ }^{(c)}$. De modo bem sintético, o conjunto das interações físico-químicas (sistemas físicos não orgânicos) levou às interações bio-físico-químicas (unidades biológicas) e essas, as bio-sócio-físico-químicas (relações entre as unidades biológicas)(12,15,19), até a espécie Homo sapiens, que representa um estado de consciência bio-sócio-físico-químico-espiritual|(12).

É evidente que essa evolução dos níveis de interação está por demais simplificada e reconhece que existem diversos graus de gradação, como por exemplo, a formação da cultura em outros animais e o desenvolvimento da inteligência e tecnologia primitiva (uso de pedras para quebrar frutos, por exemplo). Em todos os estágios mencio- nados ocorreu à manifestação de um potencial de organização não manifesto, que através de certas situações (a transformação das condições químico-físicas do globo) conseguiu se manifestar. Pode-se pensar, sob alguns aspectos, o homem em estado patológico ou não, como um ecossistema, pois o homem é uma unidade viva constituída por uma infinidade de outras unidades vivas, as quais criam uma interação entre si e com o meio orgânico e inorgânico(4). Somente a título ilustrativo, citamos um enfermeiro que presta cuidados de Enfermagem, ou seja, permite que por meio de certas ações criem-se condições para que ocorram as manifestações de potenciais de organização num sentido de maior estabilidade dinâmica.

Antes do processo patológico, o paciente apresenta determinados aspectos físico-químicos internos, certos processos de multiplicação celular e relação entre suas células e 0 grupo microbiano, alterações fisiopatológicas no órgão afetado ou a nível sistêmico, carências relativas às necessidades nutricionais, alterações psicológicas e comportamentais em relação aos outros e que se referem ao próprio indivíduo ${ }^{(20)}$.

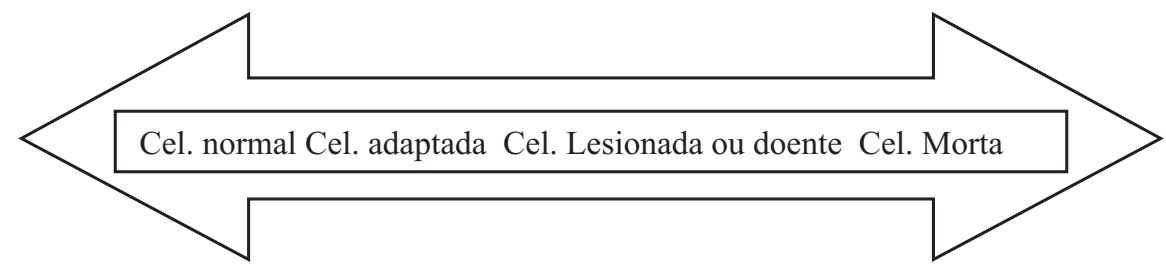

Figura 1 - Fases de saúde e doença manifestas na organização celulares

Como observado na Figura 1, houve uma alteração da condição anterior à instalação do processo patológico, o que significa que houve um deslocamento do ponto de equilíbrio. Diante desse fato, é possível verificar que o equilíbrio é muito mais delicado no paciente com uma infecção sistêmica, por exemplo, do que num indivíduo possuidor de uma dinâmica que não interfira diretamente em todos os seus sistemas orgânicos, sociais e psicológicos. Logo, se o ecossistema humano está alterado, é preciso criar condições para a manifestação do potencial organizador, no sentido de um maior grau de estabilidade dinâmica; ou seja, deve-se permitir a manifestação da lei do Cuidar: conjunto de condições que permitem a manifestação dos Potenciais de organização numa certa direção de maior estabilidade dinâmica.

(c)Populações são conjuntos de indivíduos da mesma espécie que habitam e convivem numa determinada região; biótopo é a comunidade que depende, para se manter, de fatores não-vivos ou abióticos, representados pelos com-ponentes físicos e químicos do ambiente; em seu conjunto eles formam o biótopo (do grego bios, vida e topos, lugar), que significa "o local onde vive a comunidade", o qual é constituído por elementos tais como: minerais, água, gases, umidade, temperatura, grau de luminosidade e uma infinidade de outros fatores que não cabem ser enumerados no presente trabalho; ecossistema é o conjunto vivo formado pela comunidade e pelo biótopo em interação, o qual possui características próprias e relativa estabilidade dinâmica e multifatorial.
Para perceber mais claramente a relação com a Enfermagem, pode-se rever o processo de evolução crônica da doença, que é constituído pelas seguintes etapas:

1a) Estágio em que a pessoa está em risco de desenvolver uma condição crônica devido a fator genético ou estilo de vida que aumentam a suscetibilidade da pessoa à doença crônica.

2a) Caracteriza-se pelo estabelecimento dos sintomas ou da incapacidade associada a uma condição crônica. Com freqüência, esta fase é acompanhada pela incerteza da trajetória da condição crônica à medida que os sintomas vão sendo avaliados e realizados os exames diagnósticos.

3a) Nessa fase, os sintomas e a incapacidade estão sob controle ou gerenciamento.

4a) Essa fase caracteriza-se pela instabilidade da evolução frente à recidiva dos sintomas, desenvolvimento de complicações ou reativação da doença. Durante essa fase, as atividades diárias da pessoa podem ser interrompidas pelos sintomas e pela necessidade de desenvolver novos regimes ou estratégias para controlar os problemas.

5a) A fase aguda caracteriza-se pelo início súbito de sintomas ou complicações graves ou incessantes, requerendo hospitalização para o seu controle. Essa fase pode exigir modificações importantes das atividades usuais da pessoa por algum tempo. 
6a) A fase da crise caracteriza-se por uma situação crítica ou com risco de vida, exigindo o tratamento ou o cuidado de emergência.

7aㅡ) A fase de retrocesso é marcada pela recuperação depois de um período agudo. Essa fase inclui aprender a conviver com as incapacidades ou superá-las, e no retorno a um modo aceitável de vida, dentro das limitações impostas pela condição crônica.

8a) A fase de declínio ocorre quando os sintomas se agravam ou a incapacidade progride, apesar das tentativas de controle da evolução por meio do manejo apropriado do regime. Um declínio não leva necessariamente a morte. A tendência de declínio pode ser estancada e a trajetória restabelecida em qualquer ponto, dependendo da condição e do tratamento.

9a) A fase terminal é caracterizada pelo declínio gradual ou rápido, apesar dos esforços para estancar o distúrbio ou diminuir à velocidade do declínio pelo controle da doença; ela caracteriza-se pela falha em manter as funções vitais(20).

Para evitar ou controlar o avanço da patologia são ministrados cuidados que buscam atender tanto as necessidades físicas, quanto psíquicas, emocionais e espirituais ${ }^{(20-21)}$. Na primeira, encontramos o tratamento farmacológico, o nutricional, os relativos à higiene básica e do ambiente, dentre outros. 0 segundo grupo de necessidades refere-se ao trato com o paciente e seus familiares, a importância do toque, do diálogo e do seu conforto psicológico, entre outros incontáveis cuidados.

Quando este conjunto de situações funciona em sinergia, ocorre a manifestação de potenciais de organização para um maior grau de estabilidade, que dependerá de fatores biológicos, psíquicos, técnicos, científicos e fatores complexos envolvendo situações que, muitas vezes, não conseguiremos descrever sem um alongado estudo e pesquisa. Assim, quando efetuamos cuidados, sejamos médicos, enfermeiros, nutricionistas, fisioterapeutas, mães, pais, amigos, estamos manifestando a Lei que permite a manifestação dos Potenciais de organiza-

\section{REFERÊNCIAS}

1. Darwin C. A origem das espécies. São Paulo: Hemus; 2000.

2. Kaplan D, Manners RA. Teoria da cultura. Rio de Janeiro: Zahar; 1981.

3. Dawkins R. 0 relojoeiro cego: a teoria da evolução contra o desígnio divino. São Paulo: Companhia da Letras; 2003.

4. Amabis JM, Martho GR. Fundamentos da biologia moderna. São Paulo: Moderna; 1997. ção numa certa direção de estabilidade dinâmica, buscando a mesma estabilidade que organiza os astros ${ }^{(9-10)}$, a vida ${ }^{(4)}$, a saúde ${ }^{(20)}$, a transformação, os rios, os ecossistemas ${ }^{(4)}$, o ADN ${ }^{(4)}$, as relações evolutivas... ${ }^{(1,3)}$.

Ao realizar os cuidados, o enfermeiro estimula, no paciente, a manifestação de potenciais de organização mais estáveis, que tendem a saúde. Assim sendo, o cuidado permite a manifestação de potenciais que tendem a um maior grau e, quanto maior o descuido, o nível de estabilidade é encaminhado rumo à desorganização.

Nessa compreensão da Lei do Cuidado, pode-se afirmar que ela permite a manifestação dos potenciais, sendo que quanto maior o cuidado, maior a tendência à estabilidade; no entanto, neste contexto existem múltiplas variáveis agindo, tanto a nível endógeno como exógeno.

\section{A TíTULO DE FINALIZAÇÃO}

As teorias de Enfermagem assumem o cuidar como foco de sua ação. Ao efetuarmos uma análise das teorias, percebe-se uma base comum essencial, na qual se considera que se uma parte do corpo está afetada, esta acaba influenciando a pessoa como uma entidade completa, que precisa de cuidados em diferentes aspectos ou dimensões. $\mathrm{Na}$ Enfermagem, o cuidado é orientado por um esquema subjacente, denominado processo de enfermagem, que propicia ordem e direção ao cuidado, tendo bases intelectuais sob as quais esse processo é orientado de maneira ordenada e sistemática. Os componentes essenciais do processo de enfermagem são: investigação, diagnóstico de enfermagem, planejamento, implementação, avaliação e reinvestigação (21). Todos estes passos são potenciais de organização numa direção de maior estabilidade bio-sócio-psico-espiritual da existência do indivíduo.

É possível resumir todo o exposto da Lei do Cuidar, que age tanto a nível endógeno quanto exógeno, como um conjunto de forças que permitem o prolongamento ou abreviamento de certo grau de organização, que pode ser expresso em diversos níveis, que variam da organização de um ecossistema ou movimento de elétrons, até o processo patológico no ente humano.

5. Penteado VC. Os alucinógenos e o mundo simbólico: 0 uso de alucinógenos entre os índios da América do Sul. São Paulo: EDUSP; 1976.

6. Dawkins R. O gene egoísta. Belo Horizonte: Itatiaia; 1979.

7. Brandão IL. Thomas A. Edison. Einsten. Pasteur. Newton. Franklin. Darwin. M me Curie. São Paulo: Três; 1974.

8. Bíblia Sagrada. Versão Padre Antonio Pereira de Figueiredo. São Paulo: Maltese; 1962. Mateus 18:21-35. 
9. Hazen RM, Trefil J. Saber ciência: do Big Bang à engenharia genética as bases para entender 0 mundo atual e 0 que virá depois. São Paulo: Cultura; 1999.

10. Kaku M. Hiperespaço. Rio de Janeiro: Rocco; 2000.

11. Goleman D. Inteligência emocional. São Paulo: Objetiva; 1996.

12. Zohar D, Marshall I. QS quociente espiritual: o Q que faz a diferença. São Paulo: Record; 2000.

13. Chatterji JC. A sabedoria dos Vedas. São Paulo: Pensamento; 1973.

14. Boff L. Saber cuidar: ética do humano, compaixão pela terra. Petrópolis: Vozes; 2001.

15. Civita V. M itologia. São Paulo: Abril Cultural; 1976.
16. Dumas FR. O ovo cósmico: o simbolismo da gênese universal. São Paulo: Pensamento; 1979.

17. Guirand F, Schmidt J. Mythes \& mythologie: historie et dictionnaire. Paris: Larousse-Bordas; 1996.

18. Lévêque P. Colère, sexe, rire: le Japon des mythes anciens. Paris: Les Belles Lettres; 1988.

19. Carlson NR. Fisiologia do comportamento. São Paulo: Manole; 2002.

20. Bare BG, Smeltzer CS. Tratado de enfermagem médico cirúrgico. São Paulo: Guanabara Koogan; 2002.

21. George JB. Teorias de enfermagem à prática profissional. Porto Alegre: Artmed; 2000. 